\title{
A holistic approach to population control in India
}

\author{
A JAGANNADHA RAO \\ Department of Biochemistry and Department of Molecular Reproduction, Development and Genetics, \\ Indian Institute of Science, Bangalore 560 012, India
}

(Fax,91-80-3600814; Email, ajrao@biochem.iisc.ernet.in)

India is first among the countries which adopted an official family planning programme, as early as 1950. However, fifty years later this has not prevented the population touching the one billion mark. It is obvious that despite good intentions and concerted efforts we have failed in controlling our population. Considering the seriousness of the situation it is appropriate to introspect and ascertain as to what went wrong. The problem, though very complex, can be discussed under two headings: (i) the available methods for contraception and (ii) the users. It will be evident soon that it is much easier to discuss the former rather than the latter.

It is obvious now that there cannot be an ideal contraceptive, suitable for everybody (Moudgal and Rao 1984). A careful choice has to be made among the current available methods, depending on the gender, country, socio-religious and cultural practices. According to available information the most accepted methods are the two terminal methods, vasectomy in the case of the male, and tubectomy in the case of the female (Operations Research Group 1990). These are methods of choice for all those who have completed their family size and to use them is a conscious decision made by the couple. The next most commonly used methods are the barrier methods, still popular in spite of a high failure rate. The other methods such as the use of contraceptive pills, intrauterine devices and injectables are used by a relatively small percentage of the population. It is also evident that except for the barrier method and vasectomy there are no methods available for male contraception, in contrast to the variety of methods available and in use for the female (Raja- lakshmi and Bajaj 1999). Does this mean that the available methods are not adequate for the requirements and this inadequacy is the reason for uncontrolled population growth? The answer is firmly in the negative.

The available methods are more than adequate but what is lacking is the will to use them. This brings in the philosophical question as to what is meant by will and why the will is not there. It is for this reason that it was mentioned earlier that the issue of the user is a complex one. The users are both male and female, and with limited options available to the male, the entire burden of limiting the family is shouldered by the female. However, except for a miniscule percentage of the female population, the majority are passive participants in the process with no decision-making capacity.

It is in this context that population control was given a new dimension, namely reproductive health, which to a large extent centres around the female (United Nations 1994). The concept of reproductive health recognizes the diversity of the special health needs of women before, during, and beyond child bearing age, as well as the needs of men and the quality of life of the people involved. Considering this new emphasis, it is evident that population control programmes and reproductive health go hand in hand and are interdependent. Why was there a shift to reproductive health from the much-advertised Family Planning Programme? As mentioned earlier the success of Family Planning is closely linked with the reproductive health of the woman. To quote the words of eminent clinical endocrinologist and reproductive biologist Dr S Roy: "Reproductive health includes human

Keywords. Population growth; reproductive health 
health, safe motherhood, women's development, child health and development, adolescent sexuality, adolescent education and health, effective choices of family planning prevention and management of reproductive disorders, infertility, STD's, genetic disorders and reproductive health care of the aged person" (Roy 1996). Dr Roy's statement needs to be considered carefully as it has been seen that unless each aspect is taken care of there cannot be a successful family planning programme.

It has been well documented that several factors influence reproductive health of women starting from their health during infancy, childhood, adolescent nutritional status and status in the family (Banoo et al 1996). It is common knowledge that despite claims of progress in the nation the girl child is still neglected in many communities; the opportunities for education and medical care are unsatisfactory and these have resulted in adverse effects on the general health and well-being of women. It needs to be emphasized that an important factor which has considerable influence on woman's reproductive health, is the age at which the first child is born. In spite of all the laws that exist girls are still married much earlier than the stipulated age and this has an adverse effect on physical development; they are exposed to the risks of teen-age pregnancy, for which they are not prepared both psychologically and mentally. As a consequence of repeated childbirth, they are exposed to a very high risk of ill health and death. The consequences of early pregnancy are the increases in female mortality and morbidity, which are very high in India. This is because of lack of adequate facilities for child birth as more than $20 \%$ of deliveries are carried out at home by untrained or inadequately trained personnel. Further, in cases of unwanted pregnancies, there are no facilities for safe abortion. The most ideal situation would be that every pregnancy is a planned one with every child being cared for. It is essential to recognize that an unwanted pregnancy is a specific health risk for women and their families. It can not be over emphasized that problems of street children or children who are begotten out of unwanted or unplanned pregnancy may result in neglected or abandoned children who may also have to face family violence (Roy 1996).

It should also be noted that in spite of all the regulations, there are several practices which hinder the overall development of women. Female infanticide is a still a common practice; there is a high dropout rate of girls from school. Women are discriminated against right from the cradle to the grave and even before they are born (Banoo 1996). Due to the preference for a male child, technologies like amniocentosis are used for sex determination followed by female infanticide. To quote Dr Roy again: "Women's health cannot be improved and maternal morbidity and mortality cannot be significantly reduced without the overall development of the women. The status of woman in the society reflects the status of the nation. Women are important change agents for development". A closely linked problem with women's health, development, and empowerment is the problem of child health, child survival and child development. The cumulative consequence of an early pregnancy, child bearing at an young age, the lack of decision-making capacity and unsafe abortions, is the high rate of child death, be it during pregnancy or later. High rates of child death also result in high birth rates, leading to a vicious cycle associated with rapid population growth and increase in maternal mortality and morbidity (WHO 1994). The child who survives in spite of the odds develops into a child with poor health, is malnourished, and often, is unwanted. When children reach adolescence - a very critical stage in human development - the lack of information an adolescence and sex education - results in children who display deviant behaviours. If not corrected at the right time, the problems of juvenile delinquency could result in these children.

It is evident from the discussion above, that the central point in this is the woman's health, be it general health or reproductive health. This is possible only when she has the opportunity for education, which will provide her with a decision-making capacity, which is the key to the rest of her development and future. Coming back to the question with which we started, what is wrong with our population control programme is that unless the status of women in society is improved there is no hope of curtailing our population growth. The woman alone should decide what method to choose, when to choose and how many children she wishes to have. Her status in society is the key to the success of the population control programme in India.

Having identified the problem, the obvious question to ask is what is the solution? Are we in such a situation that there is no hope? With the population crossing the one billion mark and birth the rate hovering around 3\%, the situation is still grim.

It should be noted that although $89 \%$ of the people favour the use of contraceptives, only $45 \%$ account for actual users (Roy 1996). Thus more than 50\% of the people have yet to be covered with the available methods. As mentioned earlier, the educational status of women and the age at which they are married has a direct relationship to compliance with contraceptive usage. Also, due to the fear of problems of child survival, there is a fear of adopting terminal methods. Considering the present rates of maternal morbidity and child survival, these fears are justified. However, it should be possible to educate people about other effective methods like copper IUD, oral pills, injectables and steroid hormonal contraceptives. Finally, there is still no effective method for male contraception other than vasectomy, which is a terminal method. Thus there is an urgent need to develop newer, 
more effective, suitable methods of contraception for the male.

The key to the successful implementation of the family planning programme is the effective communication skill of providers who motivate potential users. The job of the field worker will be much easier if he or she can convince people that contraception is a better option than the risks faced due to repeated pregnancy. Considering the large percentage of illiteracy in rural areas, there is an urgent need to improve the literacy rates particularly that of the women. There is also an immediate need to improve the conditions of primary health care centres, which are the nodal points for any reproductive health activity. Due to the lack of basic as well as transportation facilities in case of emergencies, thousands of patients particularly women and newborn children die following delivery or unsafe abortion and even dehydration in the case of children (Sengupta and Debabrata 1996). A national consensus has to be arrived at to uplift the facilities of the primary health care centres so that maternal and child mortality is reduced, if not totally prevented. It has been well documented that the uncertainty of child survival is the one reason which drives people to have more children as a means of security for old age in India.

India's population growth is a cause of worry, but the problem is not one without solutions. But regulations will not help solve the problem. The sense of responsibility should come from within every individual. While the educated male should change his attitude towards his female counterpart, granting her the dignity which is due to her, there is also an urgent need to change the status of the millions of underprivileged, illiterate women who are discriminated. Unless they are involved in the decisionmaking process, there is little hope for the future.

\section{References}

Banoo J C 1996 Women's reproductive health in India; in Perspectives in reproductive health (New Delhi: New Age International) pp 73-84

Moudgal N R and Rao A J 1984 Contraception through immunization and regulation of luteal function (ed.) David Puett (New York: Publication of United Nations Fund for Population Activities) pp 73-79

Operations Research Group 1990 Family planning practices in India: Third all India survey (1988-89), (Baroda: Operations Research Group)

Rajalakshmi M and Bajaj J S 1999 Male contraception: present and future (eds) M Rajalakshmi and P D Griffin (New Delhi: New Age International) pp 177-188

Roy S 1987 Experience in the development of hormonal contraceptive for the male; in Recent advances in human reproduction (ed.) R H Asch (Sulla Piproduzione Umana: Fondazione per Gli Studi) pp 95-104

Roy S 1996 Dimensions of reproductive health; Opportunities and challenges; in Perspectives in reproductive health (eds) J Sengupta and D Ghosh (New Delhi: New Age International) p. 146

Sengupta J and Debabrata G (eds) 1996 Perspectives in reproductive health (New Delhi: New Age International)

United Nations 1994 Report of the International Conference on Population and Development, Cairo, Egypt (New York: United Nations)

WHO 1994 Maternal health and safe motherhood research progress report (1987-92) (Division of Family Health, World Health Organization, Geneva) 